\title{
Adaptive BEM for Low Noise Propeller Design
}

\author{
R.M.A. Marretta ${ }^{*}, 1$, C. Orlando ${ }^{1}$ and M. Carley $^{2}$ \\ ${ }^{I}$ Dipartimento di Tecnologie ed Infrastrutture Aeronautiche, Università di Palermo, Italy \\ ${ }^{2}$ Department of Mechanical Engineering, University of Bath, UK
}

\begin{abstract}
A potential-based Boundary Element Method is presented for the aerodynamic and acoustic design of propellers at on- and off-design point conditions. Using an adaptive method, a family of airfoil sections is selected to produce the required performance (thrust, torque and efficiency versus advance ratio) at different cruise flight levels. Climb conditions are also considered in order to check the off-design point performance. Once the available airfoil data have been stored in a database, the code processes the families of airfoils to generate a complete geometry for a propeller of the specified performance with an optimized noise emission. The computational scheme adjusts the blade geometry (radial distribution of chord, local sweep angle and thickness) under the control of an optimization routine. The geometric data and pressure distribution are then used in the acoustic calculation, based on the Ffowcs Williams-Hawkings equation. Results are presented demonstrating the application of the technique and the resulting aerodynamic performance and noise output.
\end{abstract}

\section{INTRODUCTION}

A principal goal of modern aircraft powerplant design is the reduction of noise. While propeller noise has been studied for over eighty years (Lynam and Webb [1]), it is only with increasingly restrictive noise and environmental regulations that the area has become of central importance in the development of new designs for civil aircraft especially for those having propeller propulsion. The design of low-noise aerodynamically efficient powerplant requires accurate models for noise generation and propagation and suitable aerodynamic prediction methods for the fluid-dynamic quantities on the propeller.

The theoretical basis of aerodynamic noise prediction is the work of Lighthill [2], and for propellers, of Ffowcs Williams and Hawkings [3]. The state of the art now allows accurate noise predictions for an isolated propeller using various implementations of the Ffowcs Williams-Hawkings equation such as the frequency domain techniques of Hanson [4] and the time-domain approach of Farassat [5, 6]. The formulae used are exact, within linear acoustic theory, and their precision is limited only by the accuracy and resolution of the input aerodynamic data.

The problem of noise generation by a propeller operating in a mean flow, whether isolated or installed [7], is now quite well understood, the integration of acoustic criteria in propeller design methods has not been widely studied. Numerical studies have focused on the main factors affecting the performance of propellers in various configurations [814] and models have been developed which allow the prediction of propeller aerodynamics at relatively low computational cost, in particular using time domain panel methods

*Address correspondence to this author at the Dipartimento di Tecnologie ed Infrastrutture Aeronautiche, Università di Palermo, Italy;

E-mail: romario@unipa.it
$[15,16]$ which allow for the inclusion of unsteadiness effects due to oscillation and blade deflection. Comparison with measurements on rotors in hover [17] have shown that quasisteady models give good results for unsteady aerodynamics. This justifies the use of hybrid methods using free wake analysis (FWA) and boundary element methods (BEM) for the aerodynamics of propellers $[18,19]$.

This paper extends existing techniques to integrate BEM for compressible aerodynamics and a noise prediction method into a code for propeller design which generates a blade geometry for the required propeller operating conditions, taking account of the noise generated by the system. A database of data for different families of airfoils is used in conjunction with the BEM to adaptively generate a blade geometry which has the required radial distribution of circulation. This also requires the radial variation of blade pitch, incidence and sweep. The geometry is then processed to yield the blade pressure distribution at various flight conditions, which can then be used to compute the radiated noise.

This paper presents the results of a study in two stages:

1. A BEM formulation for the aerodynamics of a tractor propeller, used to generate a propeller design;

2. An acoustic calculation for the noise from the geometry generated in the first stage.

The work presented considers the case of an isolated propeller, i.e. without including the effect of scattering from an aircraft fuselage. It should be noted that previous work by the authors has presented a method for the inclusion of such effects [20] and that they can be included if an aircraft geometry is available.

\section{FORMULATION OF THE PROBLEM}

As in previous work [20-23], a BEM is used to predict the aerodynamics for each radial station of an isolated propeller. 
The complete loading distribution is then used in a time-domain prediction of the resulting noise, to give a complete analysis of the factors governing entry into service of a new design.

\subsection{Aeroacoustic Prediction}

The method used for the acoustic calculations of this paper is that of Carley $[24,25]$ which is a model for the noise generated by a rigid body undergoing arbitrary motion in a uniform flow. The development of the model is summarized here and can be found in more detail in [24].

$$
\begin{aligned}
& \left(\frac{D^{2}}{D t^{2}}-c^{2} \frac{\partial^{2}}{\partial x_{i}^{2}}\right) \rho^{\prime}= \\
& \frac{D}{D t}\left[\rho_{0} v_{n} \delta(f)\right]-\frac{\partial}{\partial x_{i}}[l \delta(f)]+\frac{\partial^{2} T_{i j}}{\partial x_{i} \partial x_{j}}
\end{aligned}
$$

In this wave equation, the body surface is defined by $f(x)=0$, with $f<0$ inside the surface $S$ and $f>0$ outside $S$. The surface normal fluid velocity is $v_{n}$, the force exerted on the fluid by the blade surface is $\boldsymbol{l}$ and the tensor $T_{i j}$ (the Lighthill tensor) is related to the shear stresses in the fluid. The uniform flow velocity (of arbitrary direction) is $\mathbf{U}$, the mean fluid density is $\rho_{0}$, the speed of sound $c$ and the flow Mach number $\mathbf{M}_{\infty}=\mathbf{U} / c$. Here the three source terms are referred to as "thickness", "loading" and "quadrupole" respectively. The first of these is related to the displacement of fluid by the propeller blade and is proportional to $\rho_{0} v_{n}$ the momentum injection at the blade surface, while the loading term is related to the force applied by the blade to the fluid. The third term is only of importance when strong non-linear effects are present and can be neglected for subsonic propellers [26]. Eq. (1) can be solved using the Green's function given by Garrick and Watkins [27] for acoustic radiation in a uniform flow

$$
\begin{aligned}
& G=\frac{\delta\left(\tau-t+\frac{R}{\left(1-\mathbf{M}_{\infty}^{2}\right) c}-\mathbf{M}_{\infty} \cdot \frac{(\mathbf{x}-\mathbf{y})}{\left(1-\mathbf{M}_{\infty}^{2}\right) c}\right)}{4 \pi R} \\
& R=\sqrt{\left(1-\mathbf{M}_{\infty}^{2}\right)(\mathbf{x}-\mathbf{y})^{2}+\left(\mathbf{M}_{\infty} \cdot(\mathbf{x}-\mathbf{y})\right)^{2}}
\end{aligned}
$$

The notation of the Green's function has been modified to allow an arbitrary inflow direction. The solution of the wave equation is then a convolution of the source terms with the Green's function which can be evaluated with the aid of generalized function methods [28] to yield the solution for loading and thickness noise, $p_{L}^{\prime}$ and $p_{T}^{\prime}$ respectively, in terms of integrals over the blade surface

$$
\begin{aligned}
& 4 \pi p_{L}^{\prime}=\frac{1}{c} \int_{S}\left[\frac{1}{1-\mathbf{M}_{s} \cdot \mathbf{D}} \frac{d}{d \tau}\left(\frac{\boldsymbol{l} \cdot \mathbf{D}}{R\left(1-\mathbf{M}_{s} \cdot \mathbf{D}\right)}\right)\right] d S \\
& -\int_{S}\left[\frac{\boldsymbol{l}}{R\left(1-\mathbf{M}_{s} \cdot \mathbf{D}\right)} \cdot\left(\frac{\mathbf{R}}{R}-\frac{\gamma}{c} \frac{\dot{\mathbf{R}}}{1-\mathbf{M}_{s} \cdot \mathbf{D}}\right)\right] d S \\
& 4 \pi p_{T}^{\prime}=\gamma \int_{S}\left[\frac{1}{1-\mathbf{M}_{s} \cdot \mathbf{D}} \frac{d}{d \tau}\left(\frac{\rho_{0} v_{n}\left(1-\mathbf{M}_{\infty} \cdot \mathbf{D}\right)}{R\left(1-\mathbf{M}_{s} \cdot \mathbf{D}\right)}\right)\right] d S \\
& -\gamma c \int_{S}\left[\frac{\rho_{0} v_{n} \mathbf{M}_{\infty}}{R\left(1-\mathbf{M}_{s} \cdot \mathbf{D}\right)} \cdot\left(\frac{\mathbf{R}}{R}-\frac{\gamma}{c} \frac{\dot{\mathbf{R}}}{1-\mathbf{M}_{s} \cdot \mathbf{D}}\right)\right] d S
\end{aligned}
$$

In this equation, the following terms are defined

$$
\begin{aligned}
& \mathbf{R}=\frac{\partial R}{\partial x_{i}} \\
& \mathbf{D}=\mathbf{R} /\left(1-\mathbf{M}_{\infty}^{2}\right)+\mathbf{M}_{\infty} /\left(1-\mathbf{M}_{\infty}^{2}\right) \\
& \mathbf{M}_{s}=\dot{\mathbf{y}} / c \\
& \boldsymbol{l}=p \mathbf{n} \\
& \gamma^{2}=\frac{1}{1-\left|\mathbf{M}_{\infty}\right|^{2}}
\end{aligned}
$$

where $p$ is the pressure on the blade and $\dot{\mathbf{y}}$ is the velocity of a point on the blade surface; while in calculating the acoustic integrals all quantities on the blade are evaluated at the retarded time $\tau$, where

$$
\tau=t-\frac{R}{\left(1-\mathbf{M}_{\infty}^{2}\right) c}+\mathbf{M}_{\infty} \cdot \frac{(\mathbf{x}-\mathbf{y})}{\left(1-\mathbf{M}_{\infty}^{2}\right) c}
$$

Note that in the formulation as presented, no restriction has been placed on the loading or the surface velocity. If unsteady aerodynamic data are available, they can be used in the noise prediction, allowing the method to be extended to unsteady problems such as flight at incidence or the inclusion of installation effects, where asymmetric loading is known to efficiently radiate noise [29].

A numerical code, described in [25] has been written to implement the method of Eq. (4). The inputs to the code are a blade mesh and loading distribution along with the operating conditions (flow velocity and direction, propeller rotation speed, etc.). At each time step, the retarded time equation is solved using a Newton-Raphson method to find $\tau$. The relevant source properties (instantaneous blade loading and radiation direction) are then calculated. Once the required quantities have been evaluated at each mesh point, the acoustic integrals are evaluated over the blade surface. The only difficulty arises when the blade motion is supersonic but this is not a consideration in this work.

\subsection{Aerodynamic Prediction}

In order to find the solution for this problem at issue, it is necessary to analyze and compute the aerodynamic variables of the propeller blade. For this aim, a devoted computational routine scheme based on a BEM approach is applied to the propeller in isolated configuration. This iterative method is based on a suitable criterion in which the imposed radial blade circulation has been satisfied through processing all the available airfoil section families previously stored into a "calling" database available for the main code. When the BEM-based routine runs and processes all the available airfoil sections database, a matching procedure is able to identify - among those airfoil families - the selected airfoil sections which guarantee the prescribed and imposed radial blade circulation and the final propeller performance for different flight conditions. 
The main body of the proposed BEM approach presented in this paper contains a general potential-based formulation through boundary integral equations for the analysis of quasisteady three-dimensional low-speed, inviscid, attachedflow problems. The direct approach presented is capable of obtaining the integral equations and addressing in detail the problem of nonuniqueness of the three-dimensional steady flow. The Kutta condition is applied to resolve the problem of determining the distribution of circulation around each wing section. Nowadays, the most commonly employed potential-based methods to solve numerically steady and unsteady flow problems [13, 30-33] use different boundary conditions and the relative numerical scheme treat constant or linear order of discretization, e.g. panel methods, boundary element methods [30, 34-42]. Bassanini et al. [43] have provided a very robust method for solving the flow nonuniqueness when boundary integral formulations, dealing with external flows, are combined with primitive variables obtained from purely kinematical considerations. Guidelines are provided by Hsiao [44] who, starting from the streambased approach for incompressible and inviscid steady flows, reached the same conclusions of references [33, 43-45] which face the problem in terms of potential velocities. These authors are in agreement on the need to impose a finite velocity at the trailing edge. In a different way, according to these authors, Davì et al. [22, 23] have proposed a potentialbased formulation in which, through the analysis of the trailing edge condition, the flow nonuniqueness was highlighted. Here, the boundary integral equations, following reference [46], are obtained by the direct method and a linear system of algebraic equations, in which the unknowns are the nodal control point potentials, is obtained. Consequently to the alternative theorem which is a corollary of the basic Fredholm theorem [47], the strategy is to keep the general flow solution as a superposition of a particular solution related to a nonlifting body embedded in a freestream having a velocity different from zero, with a non trivial solution which is obtained by considering the lifting body without the free stream. When the superposition is imposed, only inside the non-regular potential solution one may easily find a relationship between the circulation around each section and the non trivial solution itself. Here, the statements of Tricomi [47]: in the non trivial domain any non trivial solution is related with a value of general solution (for us the circulation around the lifting body not embedded in the free stream) and so, the problem of retrieving the solution uniqueness is to be resolved (for our point at issue, the flow uniqueness can be uniquely determined when the Kutta condition is assigned). As mentioned above, in order to resolve the lifting problem one has to consider a discontinuity surface for the potential, namely the wake past the body. Following Bassanini et al. [48]., the initial value of the vortex layer density $\gamma_{\mathrm{TE}}$ at the trailing edge is taken to be finite (via suitable limit procedure) as the difference between the corresponding components of the flow velocities tangential to the profile. These must be computed as part of the general solution. One may note that $\gamma_{\mathrm{TE}}$ is non-zero even when the profile has distinct tangents at the trailing edge. All this leads to the (wellknown) Kutta condition for the steady case, which requires
$\gamma_{\mathrm{TE}}$ to vanish and velocities to be finite at the trailing edge. Generally, it is useful to assume the vanishing of the pressure difference at the trailing edge. Additionally, in threedimensional problems, if the circulation is modeled by a vortex distribution, the Kutta condition may be expressed again through the assumptions featured by Bassanini et al. [48]; accordingly, the vorticity is no longer everywhere zero, as in two-dimensional flow, but it is concentrated on a smooth surface (vortex sheet, or wake). Particularly, to retrieve the flow uniqueness, a more convenient and three-dimensional form of the Kutta condition will be applied.

Following Ardito Marretta et al. [20], the velocity potential $\phi$, at first, for incompressible, inviscid and irrotational flow having free-stream velocity $U_{\infty}$ in the domain $\Omega_{e}$ around the propeller blade with boundary $\partial \Omega_{b}$, is given by

$\nabla^{2} \phi=0 \quad$ in $\Omega_{e}$

The boundary conditions on $\partial \Omega_{b}$ require that

$\frac{\partial \phi}{\partial n}=U_{n} \quad$ in $\partial \Omega_{b}$

$U_{n}$ being the velocity component along the inwardly directed normal $n$ to the boundary. The integral representation of the potential for non-lifting bodies is

$$
c \phi=\int_{\partial \Omega_{b}}\left(\phi \frac{\partial G}{\partial n}-G \frac{\partial \phi}{\partial n}\right) d s
$$

where $G$ is the singular solution of unlimited domain $\Omega_{e}$ and the coefficient $c$ is given by

$$
c=\int_{\Omega_{\infty}} \nabla^{2} G d \Omega+\int_{\partial \Omega_{b}} \frac{\partial G}{\partial n} d s
$$

By assuming the wake as a surface of discontinuity for the potential $\phi$, taking into account the no-penetration condition on the wake, the following boundary integral equation for the lifting problem is obtained

$c \phi=\int_{\partial \Omega_{b}}\left(\phi \frac{\partial G}{\partial n}-G \frac{\partial \phi}{\partial n}\right) d s+\int_{\partial \Omega_{w}} \Delta \phi \frac{\partial G}{\partial n} d s$.

The Eq. (15) is the integral equation for the potential flow around the lifting body - once given the wake geometry $\partial \Omega_{w}$ - and the jump in potential, $\Delta \phi$, on the wake. Following Davì et al., [21] when Eq. (15) is written at a point of discontinuity of the potential, i.e., the trailing edge of the blade airfoil section, one obtains via a suitable limiting procedure

$$
\begin{aligned}
& c \phi_{T E}=c_{I} \phi_{T E}^{-}+c_{I I} \phi_{T E}^{+}= \\
& \quad \int_{\partial \Omega_{b}}\left(\phi \frac{\partial G}{\partial n}-G \frac{\partial \phi}{\partial n}\right) d s+\int_{\partial \Omega_{w}} \Delta \phi \frac{\partial G}{\partial n} d s
\end{aligned}
$$

In Eq. (16) $\phi_{T E}^{-}$and $\phi_{T E}^{+}$are the different potentials on the lower and upper side at the trailing edge point, respectively, 
while $c_{I}$ and $c_{I I}$ are the coefficients which are obtained once the direction of the wake at the trailing edge is known. The condition of the potential jump continuity at the trailing edge $[20,31,43,46,48]$, i.e., the classical trailing edge condition, implies $\Delta \phi_{T E}$ on the wake must be equal to the potential jump at the trailing edge of the body

$\Delta \phi_{T E}=\phi_{T E}^{+}-\phi_{T E}^{-}$.

By using Eq. (17), since $c=c_{I}+c_{I I}$, from Eq. (16) one obtains

$$
\begin{aligned}
c \phi= & \int_{\partial \Omega_{b}}\left(\phi \frac{\partial G}{\partial n}-G \frac{\partial \phi}{\partial n}\right) d s \\
& +\int_{\partial \Omega_{w}} \Delta \phi \frac{\partial G}{\partial n} d s-c_{I I} \Delta \phi_{T E}
\end{aligned}
$$

Eq. (18) constitutes the general integral representation for the lifting problem and it explicitly shows the contribution of the potential jump at the trailing edge. Eq. (18), together with prescribed boundary data, should be sufficient to determine the remaining boundary data needed to characterize the solution of the problem. Since $\partial \phi / \partial n$ is known from the boundary condition, the solution depends on the potential discontinuity distribution on the wake. The solution $\phi$ can be expressed as a superposition of two solutions

$\phi=U_{\infty} \phi_{R}+\phi_{A}$

having as infinity condition

$\phi=0\left\|x^{-1}\right\|$

where $\phi_{R}$ is the particular solution related to nonlifting body with asymptotic vein $U_{\infty}$ different from zero, $\phi_{A}$ is the nontrivial solution associated with lifting body in absence of asymptotic stream. From Eq. (18), the two functions $\phi_{R}$ and $\phi_{A}$ fulfill the following integral equations

$$
\begin{aligned}
c \phi_{R} & =\int_{\partial \Omega_{b}}\left(\phi_{R} \frac{\partial G}{\partial n}-G \frac{\partial \phi_{R}}{\partial n}\right) d s \quad \text { in } \Omega_{e} \\
c \phi_{A} & =\int_{\partial \Omega_{b}} \phi_{A} \frac{\partial G}{\partial n} d s \\
& +\int_{\partial \Omega_{w}} \Delta \phi \frac{\partial G}{\partial n} d s-c_{I I} \Delta \phi_{T E} \quad \text { in } \Omega_{e}
\end{aligned}
$$

with the relative boundary conditions obtained by considering the body as rigid and impermeable

$\frac{\partial \phi_{R}}{\partial n}=\frac{1}{U_{\infty}} \frac{\partial \phi}{\partial n} \quad$ on $\partial \Omega_{b}$

$\frac{\partial \phi_{A}}{\partial n}=0 \quad$ on $\partial \Omega_{b}$.

Once the blade radial section has been discretized and denoting by $N$ the nodal points, one has to consider $N+M$ unknown potential nodal values because in $M$ nodal points at the trailing edge of each blade radial section the jump in potential implies two different potential values on the upper and lower trailing edge. When the boundary data $\phi$ on the blade section are expressed in terms of their nodal values by suitable shape functions, the potential $\phi$, the velocity $v$ and the pressure $p$ may be numerically calculated pointwise once the nodal values $\phi_{i}$ on the blade section are known. Eq. (18) can be expressed in numerical form and a linear system of algebraic equations is obtained. The $N$ resulting equations involve the $N+M$ unknown nodal potentials $\phi_{1}, \phi_{2}, \ldots \phi_{N+M}$ on the blade section and the $M$ jumps in potential $\Delta \phi_{T E 1}, \Delta \phi_{T E 2}, \ldots \Delta \phi_{T E M}$ on the wake at the $M$ nodes along the trailing edge. There, one has, via the trailing edge condition, i.e., Eq. (17)

$\Delta \phi_{T E j}=\phi_{j}^{+}-\phi_{j}^{-} \quad(j=1, \ldots, M)$

where $\phi_{j}^{+}$and $\phi_{j}^{-}$are the potential values at the upper and lower trailing edge of the $j$-station taken along the blade radial sections distribution, respectively. The solving system is reordered in such a way to lead to

$$
[A][\Phi]+[B][\Delta \phi]_{T E}=[S]
$$

where the vector $[\Phi]$ contains $N$ unknown values of the potential on the body $\phi_{1}, \phi_{2}, \ldots \phi_{N}$ and the vector $[\Delta \phi]_{T E} M$ values of the unknown jump in potential along the blade, while $[S]$ contains the contribution of the prescribed boundary data. The matrices $[A]$ and $[B]$ are the influence matrices that are obtained from the discretized version of the Eq. (18). The unknowns $[\Phi]$ are obtained by inverting Eq. (26)

$$
[\Phi]=[A]^{-1}\left([S]-[B][\Delta \phi]_{I E}\right)
$$

Eq. (27) expresses the $N$ unknown values of the potential $\phi_{i}$ in terms of the vector of the jump in potential, $[\Delta \phi]_{T E}$. Therefore, the potential and the velocity, at any point, can be expressed in terms of the unknown vector $[\Delta \phi]_{T E}$. More in detail, in the potential flow approach, one retrieves uniqueness of the solution by applying the Kutta condition. Taking $\zeta$ on the lower and upper airfoil section surface as the distance from the observed point $P$ to the trailing edge in the $j$ section, the uniqueness of the solution is retrieved by applying, following Bassanini et al. [20-23, 48], a threedimensional form of the Kutta condition, i.e., the removal of the singularity at the trailing edge

$$
\lim _{\varsigma \rightarrow 0} \varsigma^{1-\pi / \tau j} \partial \phi / \partial s=0 \quad(j=2, \ldots, M-1)
$$

where $s$ is the arc-length along $\partial C_{b}$ and $\tau$ is the outer angle at the trailing edge. It is worth noting Eq. (28) implies the continuity of the jump in potential at the trailing edge. The numerical way to assign the Kutta condition is related to the order of discretization. For the sake of simplicity, by assuming linear elements for each section along the blade radial distribution and taking equal lengths of the elements to the 
trailing edge, i.e., $\Delta_{1 j}=\Delta_{n j}$, one obtains, from the Kutta condition averaged over the upper and lower section side

$\left(\frac{\phi_{n+1}-\phi_{n}}{\Delta_{n}}\right)_{j}=\left(\frac{\phi_{1}-\phi_{2}}{\Delta_{1}}\right)_{j}$.

By doing so, we may now write

$\Delta \phi_{T E j}=\phi_{n}-\phi_{2}=\Gamma_{j}$

and Eq. (30) constitutes the numerical Kutta condition in the form commonly used in numerical computations with the control point located at the centroid of the contiguous element at the trailing edge. Finally, the pressure distribution along the radial blade spatial distribution is calculated from the velocity obtained by computing the gradient of the potential $\phi$. As soon as the (local) radial blade Mach number becomes equal to the critical Mach number $M_{c r i t}$ at any point along the blade (and/or each radial blade section), a devoted sub-routine adjusts the blade aerodynamic and geometrical design parameters according to the relationship

$C_{P}(r, s)=\sqrt{\frac{1}{1-M_{(r, s)}^{2}}} C_{P, 0}(r, s)$

where $r$ is the current spatial variable along the radial blade section distribution and $s$ is the local coordinate along the blade airfoil sections. $C_{P, 0}(r, s)$ and $M_{(r, s)}^{2}$ represent the local blade lift coefficient for incompressible flow and the local Mach number, respectively.

\section{AEROACOUSTIC DESIGN}

The methodology adopted to design an aeroacoustic optimal propeller consists of two main steps: $i$ ) the construction of a restricted database containing all the airfoil sections and related aerodynamic properties that match the proper radial blade circulation distribution to ensure the requested propeller performances; ii) the aeroacoustic process of all the aerodynamic allowable airfoil sections and the selection of the airfoil and its related aerodynamic properties which shows the best aeroacoustic behaviour in terms of sound pressure level at selected observation points. A block diagram of the proposed aeroacoustic propeller design approach is shown in Fig. (1) and it is intended to be applied at each isolated blade radial section.

From the same figure it is easily seen that the propeller design parameters are the in flow mach number $\mathbf{M}_{\infty}$, the rotation speed of the propeller $\Omega$, the solidity $\sigma$, the altitude $z$, the required traction $T$, the propeller diameter $D$, its number of blades $n_{\text {blades }}$ and the number of sections per blade $n_{\text {sections }}$. It is also worth noting the blade chord radial distribution is an input for the proposed procedure; thus, it is used as an "external" design parameter in such a way to obtain and check the resulting propeller performance features with respect the most convenient and reliable blade geometry from industrial, manufacturing and economical points of view. In the present study the following chord distribution along the blade radial direction has been assumed $c(r)=c_{m} \sqrt{1-\left(\frac{r-\frac{R_{T}}{2}}{\frac{R_{T}}{2}}\right)^{2}}$

where $R_{T}$ is the radius of the propeller while $c_{m}$ is computed using the solidity definition. Once the design parameters are set, the prescribed circulation in terms of lift coefficient distribution along the blade radial direction is calculated. An elliptical circulation model has been assumed for the presented study, in particular the requested lift coefficient radial function has been written as

$\bar{C}_{L}(r)=C_{L m} \sqrt{1-\left(\frac{r-\frac{R_{T}+R_{H}}{2}}{\frac{R_{T}-R_{H}}{2}}\right)^{2}}$

with $R_{H}$ being the hub radius and $C_{L m}$ is computed from the traction definition

$T=n_{\text {blades }} \int_{R_{H}}^{R_{T}}[L(r) \cos \beta(r)-D(r) \sin \beta(r)] d r$

In Eq. (34) $L$ and $D$ are the blade lift and drag distribution respectively, while $\beta$ represents the pitch angle.

The last input for the proposed aeroacoustic propeller design procedure is the airfoil database containing all the available airfoil section geometry. Once the design procedure is started, for each blade section (denoted in the block diagram of Fig. (1) by the blade radial variable $r$ ) the aerodynamic properties $\alpha$ (angle of attack), $\beta$ and $\delta$ (sweep angle) are initialized and the composed velocity $V(r)$, the chord value $c(r)$ and the first airfoil geometry are passed as input to the aerodynamic BEM code based on the previously described formulation. The aerodynamic BEM analysis gives as results the local mach $M_{L O C}$ around the airfoil boundary and the lift coefficient $C_{L}$. At this point, the BEM outputs enter into two parallel conditions check loops. On one hand, the local Mach numbers are used to check if compressibility corrections must be taken into account and if the sweep angle needs to be increased. Moreover, if the sweep angle reaches its maximum prescribed value, the current airfoil will be skipped and the procedure will restart with the next airfoil stored in the airfoil database. On the other hand, if the computed lift coefficient $C_{L}$ matches quite well with the requested one $\bar{C}_{L}$ (in this study a $5 \%$ tolerance has been used), the airfoil geometry, aerodynamic properties and pressure distribution around the airfoil boundary will be stored in the "aerodynamically optimized airfoil sections and properties database" and the procedure will restart with the next airfoil section of the airfoil database. Whereas, if the condition on $C_{L}$ is not fulfilled, the procedure will increase the pitch angle and recall the aerodynamic BEM code until the angle of attack will reach its maximum prescribed value. Even in this case the current airfoil will be skipped and the procedure will restart with the next airfoil section.

Once all the available airfoil sections stored in the database are processed, the "aerodynamically optimized database" becomes the input for the aero-acoustic code based on the previously described formulation. The sound pressure level $S P L$ at prescribed observation points are computed for 


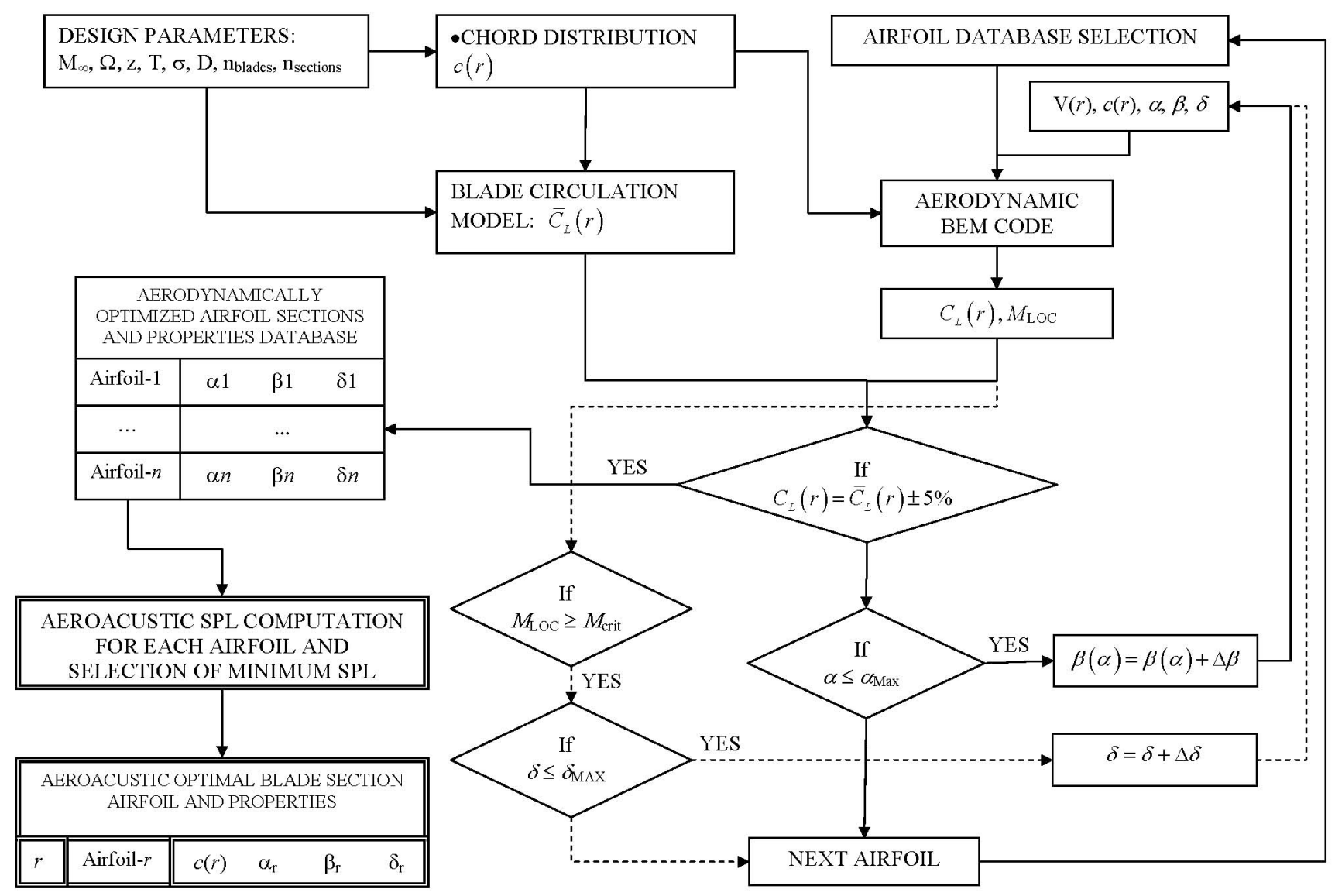

Fig. (1). Aeroacoustic design scheme.

all the airfoil sections stored in the "aerodynamically optimized database" and the one characterized by the lowest noise emission level is chosen as the aero-acoustic optimal profile for the blade section $r$ and the procedure restarts for the next blade section $r+\Delta r$. Eventually, another parameter, the blade airfoil sections arrangement, is handled to check its influence on the whole propeller noise emission behaviour. In particular, the analyzed arrangements are i) radial trailing edges arrangement, ii) elliptical aerodynamic centers arrangement and iii) radial aerodynamic centers arrangement.

\section{RESULTS AND DISCUSSIONS}

An initial test was performed to check the results generated by the aerodynamic and aeroacoustic codes against the experimental data of Šulc et al. [49]. In this paper, results were presented for the noise generated by a three-bladed wing-mounted propeller in flight. A calculation was performed for the operating conditions described in Ref. [49] and the comparison is shown in Fig. (2). Since the microphones used in the test were flush-mounted in the aircraft fuselage, $6 \mathrm{~dB}$ has been added to the predictions to account for the pressure-doubling effect of the surface. As can be seen the predictions match the experimental data quite well.

\subsection{Aerodynamic Design}

Taking into account the industrial requirements in terms of the propeller performance, the design parameters have

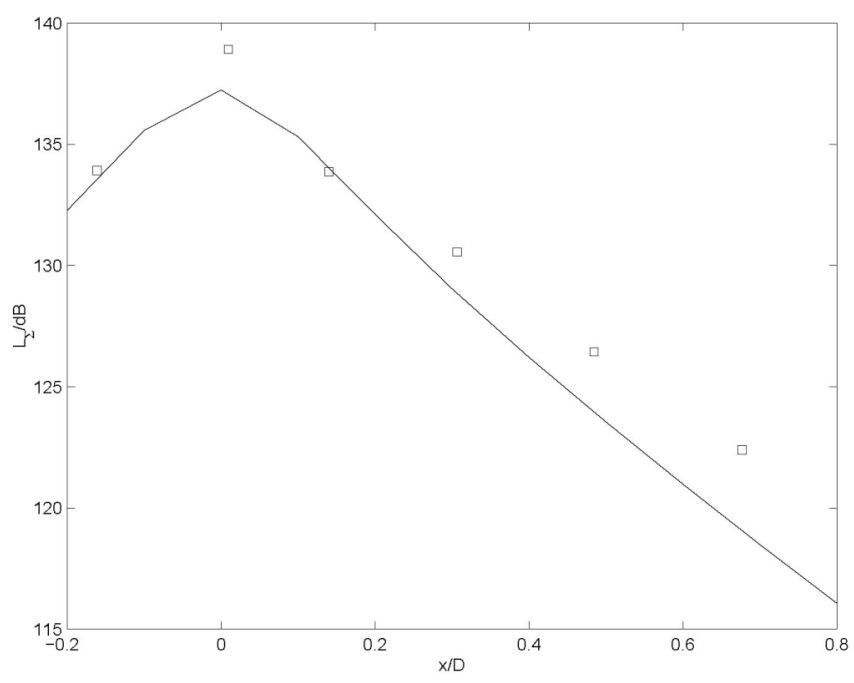

Fig. (2). Prediction (solid line) and experimental results [49] for SPL on a sideline for $R=0.6 D$.

been set (as input for the main code) using data given by ATR for its well-known turbo-prop ATR72/500 aircraft. Three different flight conditions have been chosen to aerodynamically design the propeller blade. Design parameters for the three flight conditions (climb at $0 \mathrm{ft}$, cruise at 17000 $\mathrm{ft}$ and cruise at $25000 \mathrm{ft}$ ), are shown in Tables 1-3, where

$C t=\frac{T}{\rho n^{2} D^{4}}$ 
Table 1. Climb $0 \mathrm{ft}$ Design Parameters

\begin{tabular}{|c|c|c|c|c|c|c|}
\hline & $\begin{array}{c}\text { Altitude } \\
f t\end{array}$ & $\begin{array}{c}\text { SAT } \\
K\end{array}$ & $\begin{array}{c}\text { Pressure } \\
\qquad \mathrm{kPa}\end{array}$ & $\begin{array}{c}\text { Density } \\
\mathrm{kg} / \mathrm{m}\end{array}$ & $\begin{array}{l}\text { Viscosity } \\
10^{-5} \mathrm{~Pa} \cdot \mathrm{s}\end{array}$ & $\begin{array}{l}\text { Speed of Sound } \\
\mathrm{m} / \mathrm{s}\end{array}$ \\
\hline \multirow[t]{2}{*}{ Atmospheric data } & 0 & 258 & 101.325 & 1.3684 & 1.63 & 321.969 \\
\hline & $\begin{array}{c}\text { Mach } \\
\text { Number }\end{array}$ & $\begin{array}{c}\text { Traction } \\
N\end{array}$ & $C t$ & $C p$ & $J$ & $\begin{array}{c}\text { TAS } \\
K t\end{array}$ \\
\hline ATR data & 0.242 & 17820 & 0.196 & 0.287 & 1.208 & 151.4 \\
\hline
\end{tabular}

Table 2. FL170 Design Parameters

\begin{tabular}{|c|c|c|c|c|c|c|}
\hline & $\begin{array}{c}\text { Altitude } \\
f t\end{array}$ & $\underset{K}{\text { SAT }}$ & $\begin{array}{l}\text { Pressure } \\
\qquad k P a\end{array}$ & $\begin{array}{l}\text { Density } \\
\mathrm{kg} / \mathrm{m}\end{array}$ & $\begin{array}{c}\text { Viscosity } \\
10^{-5} \mathrm{~Pa} \cdot \mathrm{s}\end{array}$ & $\begin{array}{c}\text { Speed of Sound } \\
\mathrm{m} / \mathrm{s}\end{array}$ \\
\hline Atmospheric data & 17000 & 224.32 & 52.700 & 0.7764 & 1.423 & 300.219 \\
\hline & $\begin{array}{c}\text { Mach } \\
\text { Number }\end{array}$ & $\begin{array}{c}\text { Traction } \\
\quad N\end{array}$ & $C t$ & $C p$ & $J$ & $\begin{array}{c}\text { TAS } \\
K t\end{array}$ \\
\hline ATR data & 0.415 & 10630 & 0.193 & 0.428 & 1.933 & 242.3 \\
\hline
\end{tabular}

Table 3. FL250 Design Parameters

\begin{tabular}{|c|c|c|c|c|c|c|}
\hline & $\begin{array}{c}\text { Altitude } \\
f t\end{array}$ & $\underset{K}{\text { SAT }}$ & $\begin{array}{c}\text { Pressure } \\
\qquad \mathrm{kPa}\end{array}$ & $\begin{array}{c}\text { Density } \\
\mathrm{kg} / \mathrm{m}\end{array}$ & $\begin{array}{c}\text { Viscosity } \\
10^{-5} \mathrm{~Pa} \cdot \mathrm{s}\end{array}$ & $\begin{array}{l}\text { Speed of Sound } \\
\mathrm{m} / \mathrm{s}\end{array}$ \\
\hline Atmospheric data & 25000 & 208 & 38.300 & 0.59 & 1.32 & 289.42 \\
\hline & $\begin{array}{c}\text { Mach } \\
\text { Number }\end{array}$ & $\begin{array}{c}\text { Traction } \\
\qquad N\end{array}$ & $C t$ & $C p$ & $J$ & $\begin{array}{c}\text { TAS } \\
K t\end{array}$ \\
\hline ATR data & 0.487 & 7480 & 0.176 & 0.440 & 2.189 & 274.3 \\
\hline
\end{tabular}

is the thrust coefficient,

$C p=\frac{T U_{\infty}}{\rho n^{3} D^{5}}$

is the power coefficient while the advance ratio $J$ is defined as

$$
J=\frac{U_{\infty}}{n D}
$$

In Eqs.(35-37) $T$ is the traction defined as in Eq.(34), $U_{\infty}$ is the inflow air speed, $\rho$ the density and $n$ is the propeller angular velocity. It has been assumed that the propeller has 6 blades, its disc diameter and hub diameter are $3.86 \mathrm{~m}$ and $0.25 \mathrm{~m}$, respectively, and the solidity value is 0.038 . The critical Mach number chosen to trigger the sweep condition is $M_{\text {crit }}=0.8$. The maximum sweep angle value $\delta_{\text {Max }}$ was set in such a way the location of the trailing edge of each airfoil section along the blade radius has no geometrical interference between the adjacent ones, while the angle of attack for each isolated airfoil blade section has been considered between a suitable range in which - accordingly to the required local lift coefficient - the local pitch angle of the blade section is capable to guarantee the propeller performance. The aero-acoustic design procedure has been run for the above mentioned flight conditions, from now on identified by Climb0, FL170 and FL250.

The propeller pitch and pitch angle at the $75 \%$ of the blade radius for the propellers optimized in the three flight conditions are shown in Table 4 . The aeroacoustic optimized propeller traction for the three flight conditions are shown in Table 5, where the discrepancy with respect to the requested values are also highlighted.

Table 4. Pitch [m] and Pitch Angle at $75 \%$ of Blade Radius

\begin{tabular}{|cccc|}
\hline & Climb0 & FL170 & FL250 \\
\hline Pitch Angle & $29.53^{\circ}$ & $46.3^{\circ}$ & $45.74^{\circ}$ \\
\hline Prop. Pitch & 5.95 & 9.2 & 10.49 \\
\hline
\end{tabular}

Table 5. Requested and Computed Traction [N]

\begin{tabular}{|cccc|}
\hline & Climb0 & FL170 & FL250 \\
\hline ATR & 17820 & 10630 & 7480 \\
\hline Computed & 18391 & 10697 & 7496 \\
\hline Discrepancy & $3.20 \%$ & $0.63 \%$ & $0.21 \%$ \\
\hline
\end{tabular}

Once the propeller geometry is obtained "on-design" conditions, a comparison between the requested and the computed performances lead to the conclusion that both the other "off-design" conditions are fulfilled by the adopted 6bladed propellers. According to the imposed (local) chord and lift coefficient distributions, a comparison of the aerodynamic parameters is also shown giving slight difference for those parameters (Fig. 3); again and for convenience, lift, drag, traction, torque and performance coefficients are sketched in Figs. (4-7). 


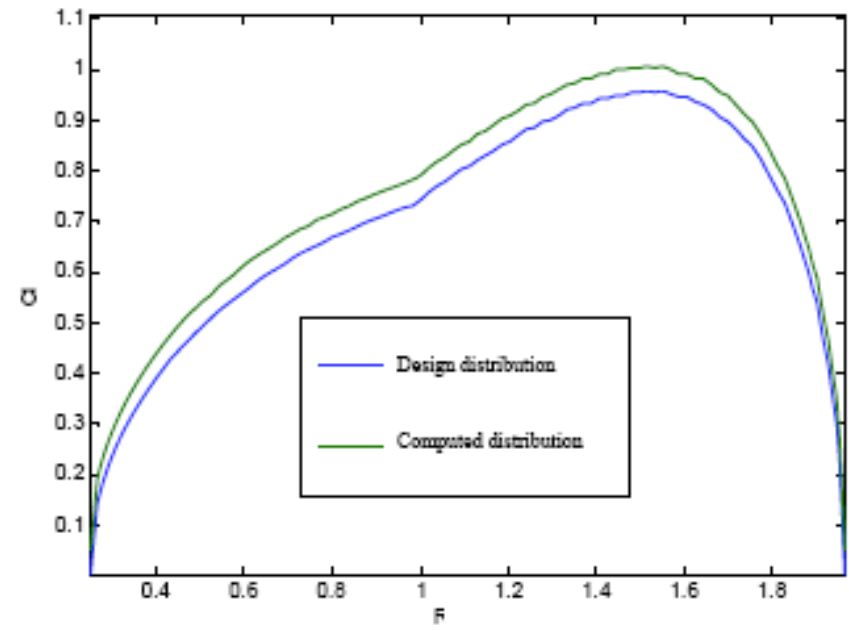

Fig. (3). Computed and requested (taking into account compressibility effect) lift coefficient along the blade radius.
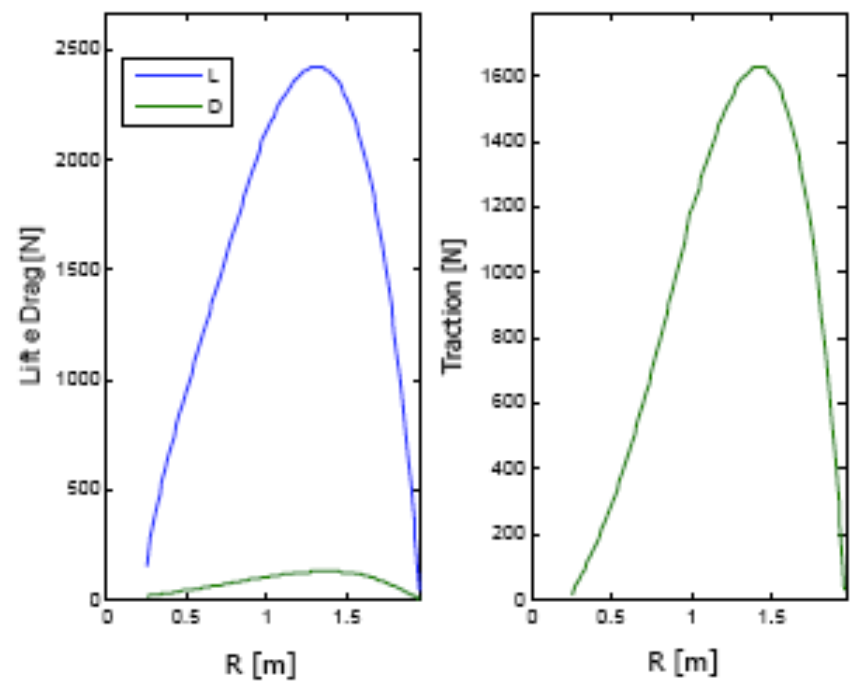

Fig. (4). Lift, drag and traction distribution along the blade radius.

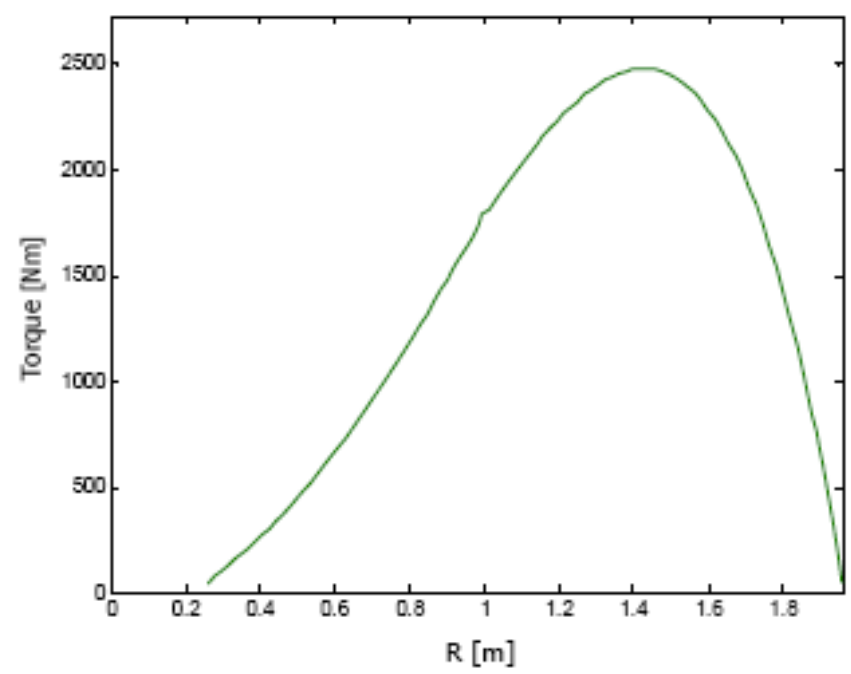

Fig. (5). Torque distribution along the blade radius.

The resulting propeller geometries are obtained having considered three distinct manufacturing processes, i.e., trailing edges along a radial axis location, aerodynamic centers location along an elliptical direction and aerodynamic cen- ters along a radial axis. These three families of propellers are able to satisfy the imposed performance characteristics by the manufacturer. Then, for the three flight conditions, a set of nine propellers is obtained. Once the devoted routine has computed the aeroacoustic responses of the final set of propellers, the final step is the comparison of the noise level among the resulting propeller geometries both in near field and in far field (1.5 radii and 15 radii along a sideline from rotational axis, respectively).

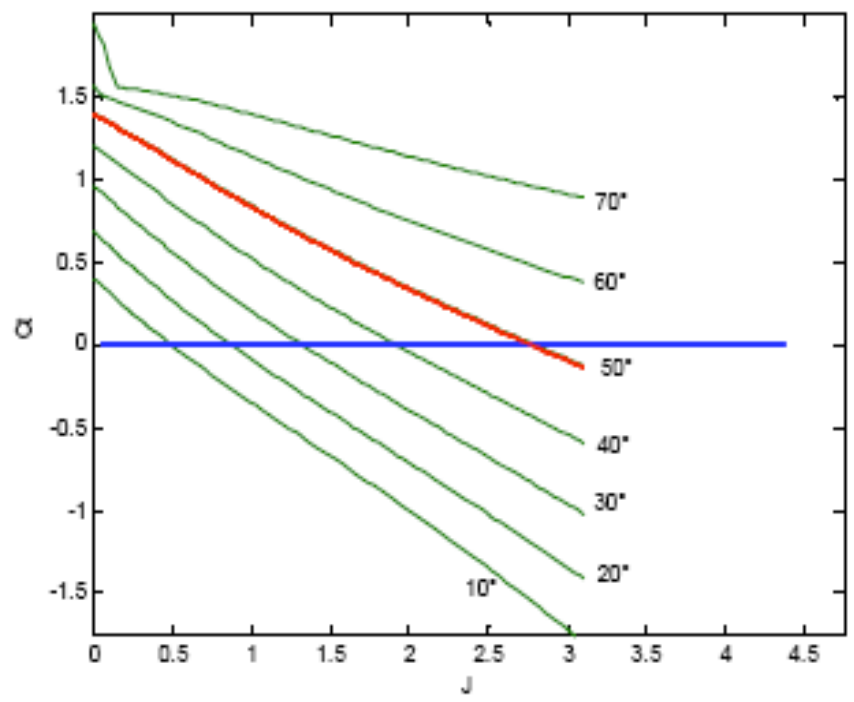

Fig. (6). Trhust coefficient as function of advance ratio and pitch angle at the $75 \%$ blade radius. Design configuration in red.

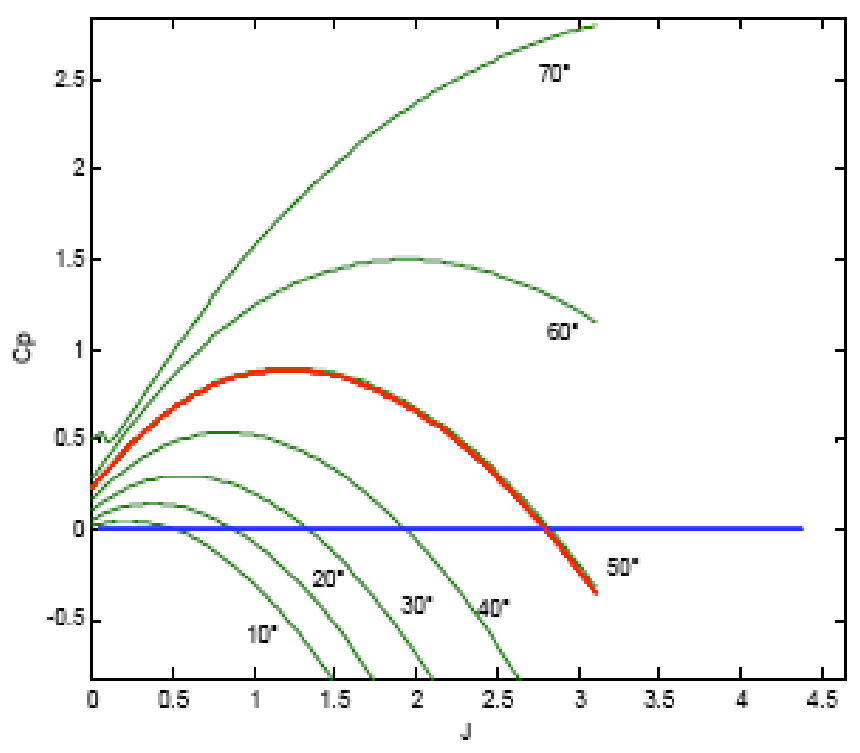

Fig. (7). Power coefficient as function of advance ratio and pitch angle at the $75 \%$ blade radius. Design configuration in red.

It is worth noting that, once those nine distinct propellers have been designed and analyzed and since three geometries arrangement for each design flight condition (Climb0, FL170 and FL250) have been taken into account, each set of three propellers is quite different from the other set at the same manufacturing process because each set of propellers is built up by different airfoil sections along the blade radius. In Figs. (8-10) FL250 propellers, obtained using the three blade airfoil sections arrangement, are shown. 


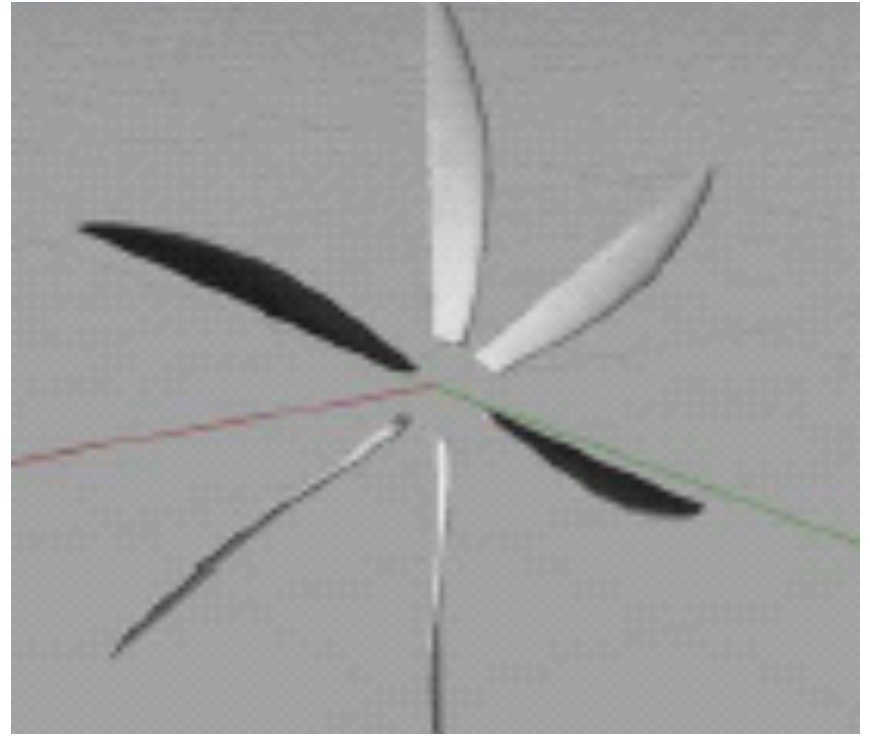

Fig. (8). Radial trailing edges arrangement.

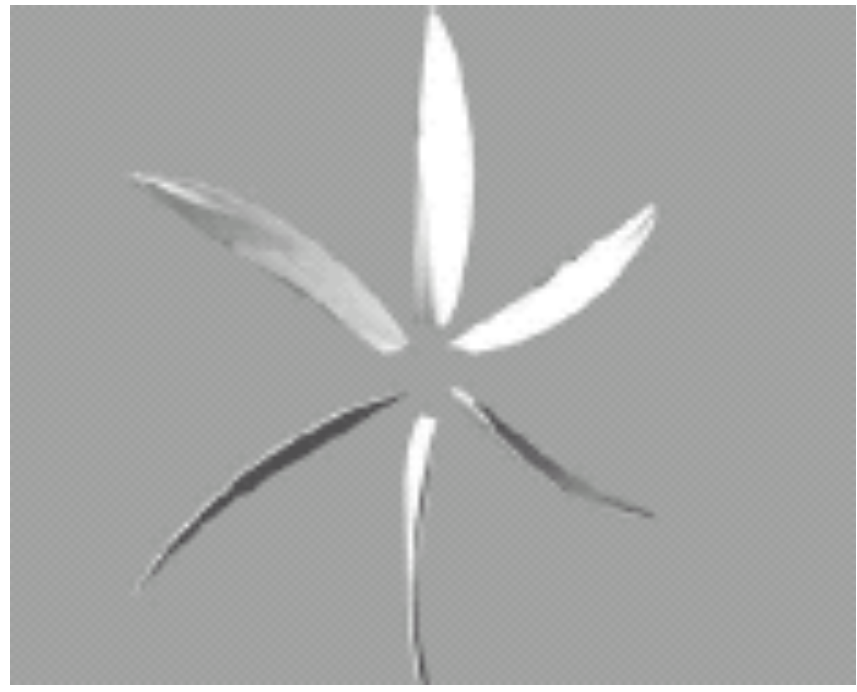

Fig. (9). Elliptical aerodynamic centers arrangement.

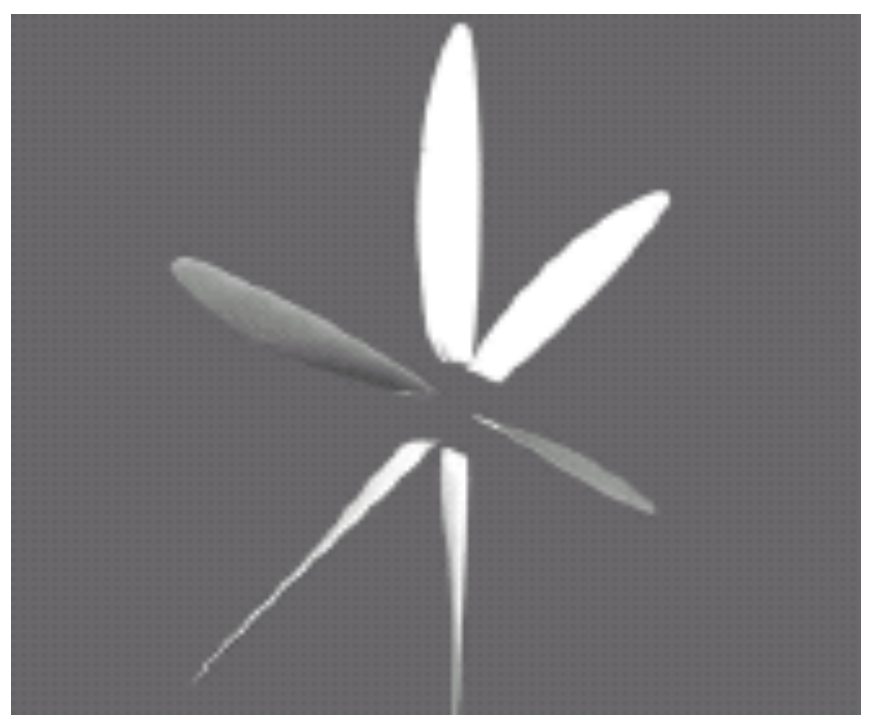

Fig. (10). Radial aerodynamic centers arrangement.

\subsection{Aeroacoustic Design}

Noise from the proposed propeller designs is assessed by calculating the radiated noise on two sidelines in the acoustic near- and far-fields. The near-field noise is computed on a line parallel to the axis of rotation, 1.5 propeller radii from the center of rotation while the far-field noise is computed 15 radii from the propeller axis. Results are presented as Aweighted Sound Pressure Level (SPL) along the sideline. The data presented are for the on- and off-design points of the Flight Level 170 propeller, using each of the three section arrangements.

Figs. (11-16) show the computed noise on the near-field and far-field sidelines for the three flight levels 250, 170 and 0 . Data are presented for the baseline case of radial arrangement of the section trailing edges and for the other two section arrangements considered. In all six cases considered, the baseline case gives the lowest overall SPL, by as much as $3 \mathrm{~dB}(\mathrm{~A})$.

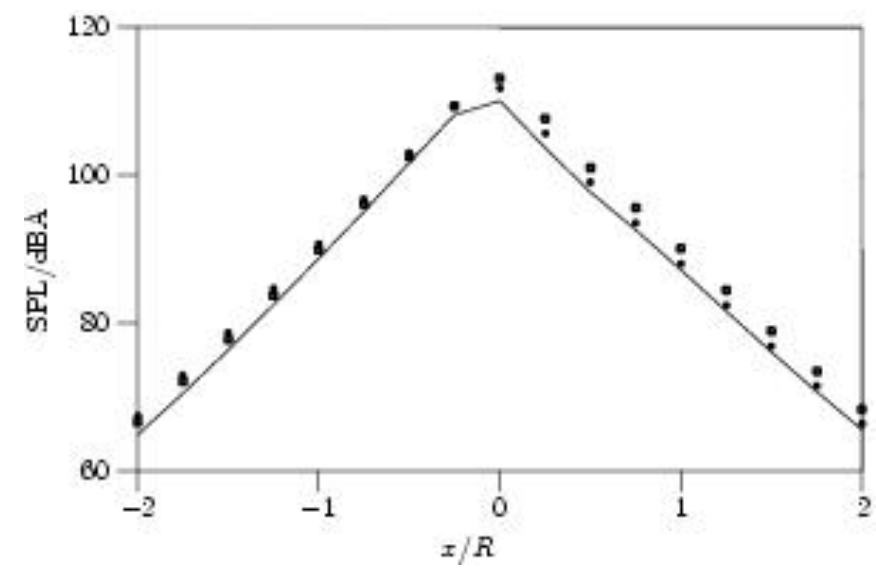

Fig. (11). Near field SPL, flight level 250, solid line radial trailing edge arrangement; circles, elliptical aerodynamic center arrangement; boxes, radial aerodynamic center arrangement.

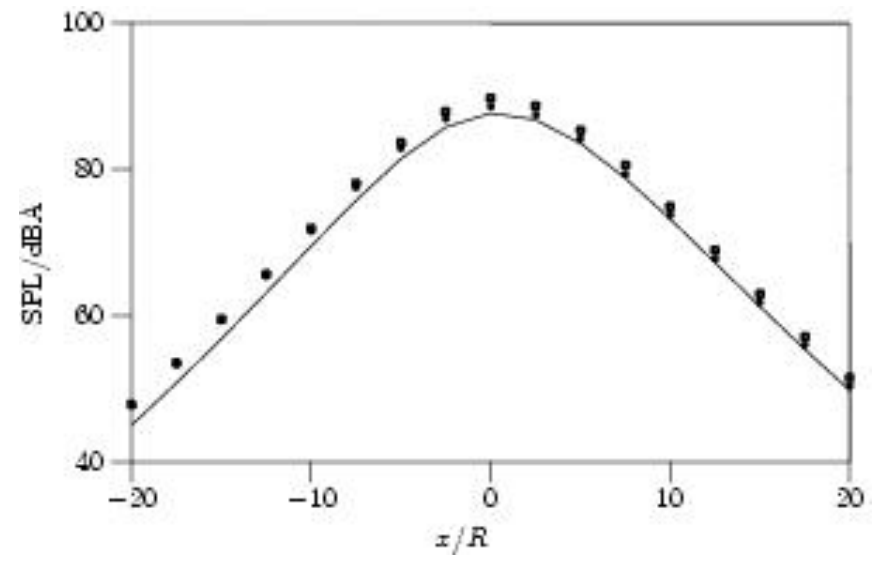

Fig. (12). Far field SPL, flight level 250, symbols as in Fig. (11).

The reasons for this advantage are unclear, given that the gross aerodynamic parameters of the propellers are quite similar, but it is most likely that the radial arrangement of sections, in this case, enhances cancellation of the noise from different radial stations. Although the benefit is relatively small, it does appear to be real and consistent. 


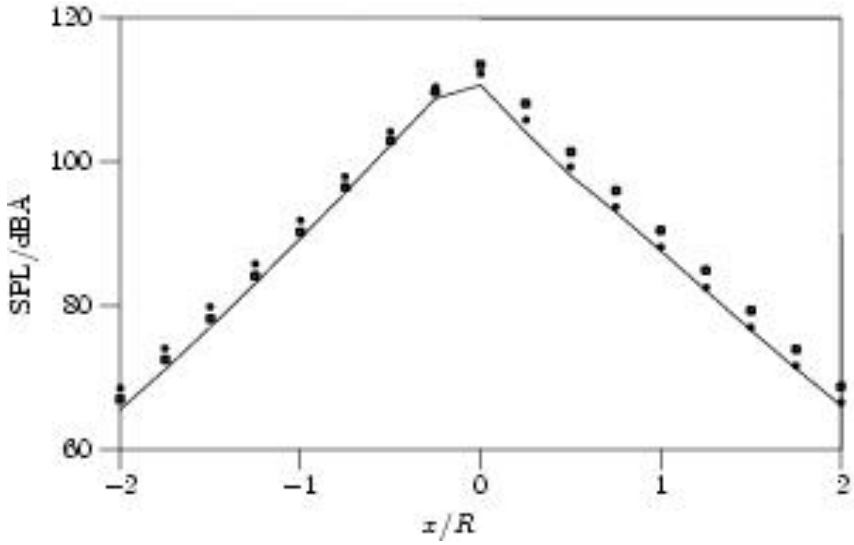

Fig. (13). Near field noise, flight level 170, symbols as in Fig. (11).

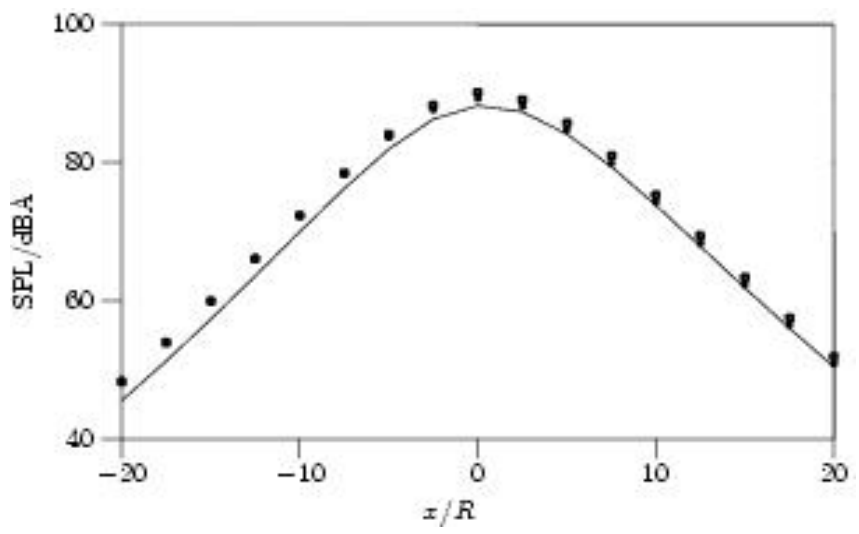

Fig (14). Far field noise, flight level 170, symbols as in Fig. (11).

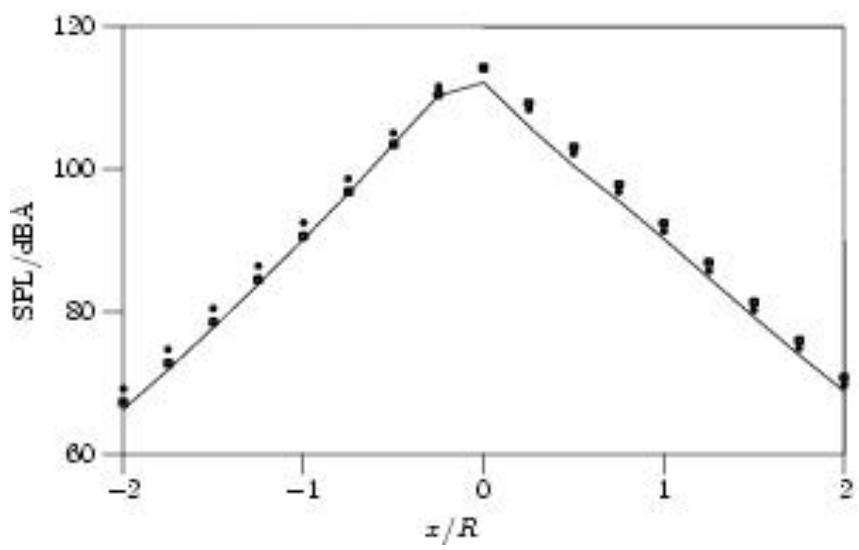

Fig (15). Near field noise, flight level 0, symbols as in Fig. (11).

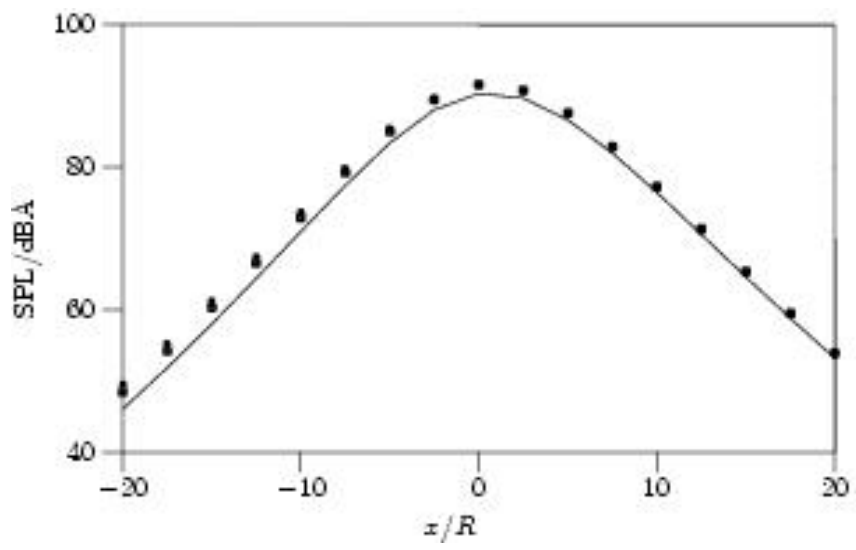

Fig (16). Far field noise, flight level 0, symbols as in Fig. (11).

\section{CONCLUSIONS}

A potential-based BEM solver has been developed for the aerodynamic and acoustic design of propellers with the capability of checking the manufacturability of the geometry. The integrated approach yields an efficient code for designing a propeller geometry which meets prescribed operating requirements, taking into account noise generation. The method has been applied to three sets of baseline operating conditions, with off-design point operation included in the design requirements. This means that the final design for each operating condition is optimized for a particular cruise flight level, but with the climb and alternative cruise flight level included as supplementary requirements, the noise being minimized in each case. The outcome of the study is a set of propeller designs generated by a balanced optimization scheme representing the full service requirements of the propeller.

\section{REFERENCES}

[1] Lynam EJH, Webb HA. The emission of sound by airscrews Aeronautical Research Committee Report 624, 1919.

[2] Lighthill MJ. On the sound generated aerodynamically, Part I General Theory. Proc Royal Soc (A) 1952; 211: 564-87.

[3] Ffowcs Williams JE, Hawkings DL. Sound generation by turbulence and surfaces in arbitrary motion. Phil. Trans. Royal Soc Lond (A) $1969 ; 264: 324-42$.

[4] Hanson DB, Woolcock AJ. Compressible helicoidal surface theory for propeller aerodynamics and noise. AIAA J 1983; 21: 881-8.

[5] Farassat F. Linear acoustic formulas for calculation of rotating blade noise. AIAA J 1981; 9: 1122-30.

[6] Farassat F. Theoretical analysis of linearized acoustics and aerodynamics of advanced supersonic propellers. Aer Acous Prop AGARD 1985.

[7] Ardito Marretta R, Davì G, Milazzo A, Lombardi G, Carley M. A procedure for the evaluation of installed propeller noise. J Sound Vibr 2001; 244(4): 697-716.

[8] Cho J, Williams MH. Propeller-wing interaction using a frequency domain panel method.. AIAA J Aircraft 1990; 3: 196-203.

[9] Chiaramonte JY, Favier D, Maresca C, Benneceur S. Aerodynamic interaction study of the propeller/wing different configurations. AIAA J Aircr 1996; 1: 46-53.

[10] Witkowski D, Lee A, Sullivan J. Aerodynamic interactions between propellers and wings. AIAA J Aircr 1989; 9: 829-36.

[11] Rottgermann A, Wagner S. Compressible potential flow around a helicopter rotor. In: Proc ICES-IABEM'95 Symp, Hawaii USA, Comput Mech 1995; 2: 2915-20.

[12] Catalano Martini F. The aerodynamic characteristics of a smooth wing at low Reynolds number under effect of a pusher propeller. In: Proc $13^{\text {th }}$ COBEM-CIDIM'95 Symp, Belo Horizonte, Brazil 1995.

[13] Kinnas AS, Hsin CY. Boundary element method for the analysis of the unsteady flow around extreme propeller geometries. AIAA J 1992; 30: 688-96.

[14] Graber A, Rosen A. Velocities induced by semi-infinite helical vortex filaments. AIAA J Aircr 1987; 5: 289-90.

[15] Yamaguchi H, Bose N. Oscillating foils for marine propulsion. In: Proc $4^{\text {th }}$ International Offshore and Polar Engineering Conference, Osaka, Japan, I.S.O.P.E. 3, 539-44.

[16] Bose N. Performance of chordwise flexible oscillating propulsors using a time-domain panel method. Int Shipbuild Progr 1995; 10(9): 432: 281-94.

[17] Müller RHG, Nsi Mba M, Aymard E, Favier D, Berton E, Maresca C. Visualization and measurement of helicopter rotor flow with swept back tip shapes at hover flight using the "flow visualization gun" time line technique. Exp Fluids 1996: 3: 161-9.

[18] Ardito Marretta RM. Performance of a propeller embedded in the flowfield of a wing. AIAA J Aircr 1996; 5: 919-23.

[19] Ardito Marretta RM, Davì G, Lombardi G, Milazzo A. Wingpropeller coupling simulation from tractor up to hover flight conditions. Comp Mod Sim Eng 1997; 2: 304-21. 
[20] Ardito Marretta RM, Davì G, Lombardi G, Milazzo A. Hybrid numerical technique for evaluating wing aerodynamic loading with propeller interference. Comp Fluids 1999; 28: 923-50.

[21] Davì G, Ardito Marretta RM, Milazzo A. Explicit Kutta condition for unsteady 2D high order potential boundary element method. AIAA J 1997; 6: 1080-1

[22] Davì G, Marretta RMA, Milazzo A. BEM formulation of the trailing edge condition. In: Proc ICES '95 Symp., Hawaii, Comput Mech '95. 1995; 2: 2933-38.

[23] Davì G, Marretta RMA, Milazzo A. BEM for the trailing edge and Kutta condition. In: Proc $13^{\text {th }}$ COBEM-CIDIM'95 Symp, Belo Horizonte, Brazil 1995

[24] Carley M. Prediction of noise generated by a propeller in a flow. $\mathrm{PhD}$ thesis, (University of Dublin, Trinity College), 1997.

[25] Carley MA. Technical report. SCRUMPI: simulation code for rotation of unsteady source multibladed propellers at incidence. Dublin: Department of Mechanical Engineering, Trinity College, 1998.

[26] Hanson DB, Fink MR. The importance of quadrupole sources in prediction of transonic tip speed propeller noise. J Sound Vibr 1979; 62: 19-38.

[27] Garrick IE, Watkins CE. A theoretical study of the effect of forward speed on the free-space sound-pressure field around propellers. NACA Report 1198, 1953

[28] Farassat F. Introduction to generalized functions with applications in aerodynamics and aeroacoustics. NASA Technical Paper 3428, 1994.

[29] Wright SE. Sound radiation from a lifting rotor generated by asymmetric disk loading. J Sound Vibr 1969; 9: 223-40.

[30] Morino L, Kuo CC. Subsonic potential aerodynamics for complex configurations: a general theory. AIAA J 1974; 12: 191-7.

[31] Morino L. Helmholtz decomposition revisited: vorticity generation and trailing edge condition, Part 1: incompressible flows. Comput Mech 1986; 1: 65-90.

[32] Poling DR, Telionis DP. The response of airfoils to periodic disturbances - the unsteady Kutta condition. AIAA J 1986; 24: 193-9.

[33] Casciola CM, Piva R. Un metodo agli elementi di contorno per l'analisi del flusso intorno ad un'ala in condizioni non stazionarie. Aerotecnica - Missili e Spazio 1989; 68: 25-31.

[34] Yon S, Katz J, Plotkin A. Effect of airfoils (trailing-edge) thickness on the numerical solution of panel methods based on the Dirichlet boundary condition. AIAA J 1992; 30: 697-702.
[35] Moran J, Cole K, Wahl D. Analysis of two-dimensional incompressible flows by a subsurface panel method. AIAA J 1980; 18: 526-33.

[36] Wang CM, Wu JC. Numerical solution of steady Navier-Stokes problems using integral representations. AIAA J 1986; 24: $1305-$ 12

[37] Piva R, Morino L. Vector green's function method for unsteady Navier-Stokes equations. Meccanica 1987; 22: 76-85.

[38] Belibasakis KA, Politis GK. A boundary integral equation formulation of the Neumann problem for a vector field in R3 with application to potential lifting flows. Eng Anal Bound Elem 1995; 16: 517.

[39] Suciu EO, Morino L. Nonlinear steady incompressible liftingsurface analysis with wake roll-up. AIAA J 1977; 15: 54-8.

[40] Cunningham Jr AM. An efficient, steady subsonic collocation method for solving lifting-surface problems. AIAA J Aircr 1971; 8: $168-76$

[41] Gennaretti M, Morino L. A Boundary element method for the potential, compressible aerodynamics of bodies in arbitrary motion. Aeronaut J 1992; 96: 15-9.

[42] Katz J, Plotkin A. Low-speed aerodynamics. McGraw-Hill International Editions, New York 1991

[43] Bassanini P, Casciola CM, Lancia MR, Piva R. A boundary integral formulation for the kinetic field in aerodynamics. part I: mathematical analysis. Eur J Mech B/Fluids 1991; 6: 605-27.

[44] Hsiao GC. Solution of boundary value problem by integral equations of the first kind - an update. boundary integral methods. Springer L, Morino L, Piva R, Eds. 1991; 231-40.

[45] Bassanini P, Casciola CM, Lancia MR, Piva R. A boundary integral formulation for the kinetic field in aerodynamics, part II: applications to unsteady 2D flows. Eur J Mech B/fluids 1992; 11(1): 69-92.

[46] Morino L. Boundary integral equations in aerodynamics. Appl Mech Rev 1993; 46: 445-86.

[47] Tricomi G. Integral Equation. Dover Publ., New York 1957.

[48] Bassanini P, Casciola CM, Lancia MR, Piva R. On the removal of the trailing edge singularity in 3D flows. Eur $\mathrm{J}$ Mech B/Fluids 1996; 15(6): 809-30

[49] Sulc J, Hofr J, Benda L. Exterior noise on the fuselage of light propeller driven aircraft in flight. J Sound Vibr 1982; 84: 105-20.

(C) Marretta et al.; Licensee Bentham Open.

This is an open access article licensed under the terms of the Creative Commons Attribution Non-Commercial License (http://creativecommons.org/licenses/by$\mathrm{nc} / 3.0 /$ ) which permits unrestricted, non-commercial use, distribution and reproduction in any medium, provided the work is properly cited. 